\title{
The companies' characteristics impact on the performance's sustainable reporting. Case study on Bucharest Stock Exchange listed companies
}

\author{
Maria-Mădălina Bogeanu-Popa ${ }^{1 *}$ and Mariana Man $^{2}$ \\ ${ }^{1}$ University of Craiova, 13 Al. I. Cuza, Craiova, România \\ ${ }^{2}$ University of Petroșani, Department of Economic Sciences, 20 Universității, Petroșani, România
}

\begin{abstract}
The actual economic environment, which is in a continuous dynamic, obligates the economic entities to rethink their periodic performance reporting method. In this context, drafting a report of interest for the stakeholders, which would contain financial as well as non-financial information, becomes a challenge. Integrating the exigencies of the sustainable development of economic, social and environment nature in a sustainable report of performance represents in the long run an indispensable requirement for any stock exchange listed company. This paper aims to analyse three characteristics of the Bucharest Stock Exchange (BSE) listed companies: dimension (ED), rentability (ARR) and company recognition (EER). The control variable (EO) is given by the objectives the company follows. The data in this paper has been collected from annual reports drafted by BSE listed companies on the Regulated Market referring to 2019. The results obtained through econometric research have revealed the fact that the objectives (EO), the dimension (ED) and the company's rentability (ARR) have a significant impact on the sustainable reporting of their performance.
\end{abstract}

\section{Introduction}

The sustainability, as seen from the economic entities' point of view, represents an intensely promoted awareness in the last few years. Through their activities, the economic entities focus on providing goods and services commercialized on a competitive market. Though, this course of action is no longer considered fit, for it does not attract by itself a sustainable approach [1]. Pressure appears on the economic entity regarding the impact on resources and climate change, aspects which exceed the limits of the traditional approach [2]. A sustainable approach represents a development concept through which all the activities are environmentally friendly, correct form a social point of view and possible from an economic point of view $[3,4]$.

The sustainable reports represent the entity's communication method regarding its sustainable actions, the level of achieved performance and the impact of the activities regarding the environment [5]. On an international level there are numerous standards for implementing sustainability practices, for instance: International Integrated Reporting

\footnotetext{
* Corresponding author: madalinabogeanu@yahoo.com
} 
Council (IIRC), Global Reporting Initiatives (GRI), Dow Jones Durability Index, ISO 14000 or ISO 26000 Standards and Social responsibility SA 8000 [4]. The economic entities in Romania are progressively headed towards implementing the sustainable development practices and implicitly towards drafting sustainable reports, given the appearance of the EU 95/2014 Directive [6].

The Bucharest Stock Exchange (BSE) has manifested its interest in the practices specific to sustainable reports, given the fact that the BSE listed entities must present in detail the risks, opportunities, and economic, environmental, and social actions [7]. Therefore, aspects such as: the relationship with the investors, the entity's objectives, the responsible actions towards the environment, social or governance are sustainable elements which constitute the main competitive advantage of the economic entity [8].

On a national level, most of the economic entities draft sustainable reports voluntarily because the legislation using European Directives imposes drafting sustainable reports only to those entities which at the date of the balance sheet register a number of 500 employees [6]. The benefits brought by sustainable reports for the economic entity are found on an internal plan as well as an external one. On an internal plan there are mentioned the integration of some policies and the balancing of the economic entity's performance, adopting a strategy and an evaluation in a real and credible business approach in the long run [9]. On an external level, the community recognition, position on the market or the competitive advantage, are highlighted [10].

Within the economic entity the management is the guarantor of implementing the sustainable development's requirements. The latter has the capacity of generating future viable and lasting social, environmental and personnel projects [11]. The sustainable reports of the entity are the effect of applying the principles of sustainability, more exactly resorting to using resources so that the entity has time continuity and profit [10]. Due to the fact that sustainability encourages for the resources to be used responsibly, it implies that the entity obtains profit in an environment in which it has to act responsibly [5].

\section{Brief Literature Review}

The results of the studies in the field have demonstrated that the sustainable reports have become an indispensable element within the economic entity's periodic reports and the present aspects such as: the entity's vision, presenting risks and the risk management method, evaluating challenges, presenting policies, presenting performance indicators and last but not least the adopted business model [12].

Authors such as Eccles et. al. [3] consider that the approach of the entity's sustainability is subjective, however the entity must choose what fits the business model and must respect the principles which lead to the understanding, accomplishment and development of sustainability as an integrating part of the business strategy.

From a financial point of view, the sustainability components can be considered capitals of it, respectively environmental capital, economic capital, and social capital [13]. An important aspect of sustainability is that of which the entity can be considered sustainable only if it manages an economic efficiency, a social fairness but also respects the environment $[13,14]$

The sustainable reports involve changing the accounting activity to accomplish the environmental, social and governance requirements and the requirements the users of financial and non-financial information follow [7,15]. One of the challenges which includes the content of the sustainable report is implementing ecological, social, and economic aspects in an interconnected functional system [16,17]. The sustainable reports assume a management strategy implemented efficiently, so that the risks are minimal, and the challenges are managed [18.19]. 
The economic entities' response to the sustainable development's exigencies has as result a favourable impact on the community, aspect presented by the entities through sustainable reports. In order to respond to this challenge, the entities act by integrating within their own strategies, elements specific to sustainable reports [20]. Numerous authors believe that sustainability can truly be integrated within the entity's strategy and opportunities if it goes through every stage of the sustainable development process [21].

Some authors consider that the sustainable reports represent the key towards a process composed of five stages to achieve general sustainability, them being: before compliance, compliance, after compliance, the integrated strategy, passion and purpose $[19,22]$.

\section{Research methodology}

For this research to be made, the qualitative and preponderantly the quantitative researches have been used. Through the qualitative research the specialty literature has been appealed to, data has been collected and interpretations have been made with the purpose of a better understanding of the analysed elements. Within the quantitative research the research results have been processed and highlighted. Judging by the volume of data that was presented, the processing of results was relevant.

The objective of this paper researches the impact of the companies' characteristics on the performance's sustainable report, in the context of the sustainable development's exigencies of the BSE listed companies.

Within this case study the following were established: a dependant variable, three independent variables and a control variable.

The dependant variable is represented by the content of the sustainable report of performance of a BSE listed economic entity (SR).

The independent variables are represented by the economic entity's dimension (ED), the economic entity's rentability (ARR) and the economic entity's recognition (EER).

The control variable used in this study refers to the economic entity's objectives (EO).

When establishing the independent variables, a series of further details, which are found in table 1 , is necessary.

Table 1. Detailing the independent variables

\begin{tabular}{|c|l|}
\hline $\begin{array}{c}\text { The economic entity's } \\
\text { dimension (ED) }\end{array}$ & $\begin{array}{l}\text { Establishing the variables } \\
\text { phis aspect is often associated with the economic entity's limits of } \\
\text { information, information of social, environmental or personnel } \\
\text { responsibility are often offered to the public by the big companies. The } \\
\text { formula used to measure the economic entity's dimension is the } \\
\text { following: }\end{array}$ \\
$\qquad$ ED = lg(total assets) \\
\hline The rentability of the \\
economic entity (ARR) & $\begin{array}{l}\text { This aspect refers to the economic entity's asset rentability, that is the } \\
\text { value of the earnings from the resources it owns. The economic entities } \\
\text { which voluntarily draft sustainable reports in conformity with the } \\
\text { international reporting framework are considered to be better performing } \\
\text { than those which draft sustainable reports but do not respect any } \\
\text { international reporting framework (GRI) [23]. } \\
\text { The rentability will be analysed whether it has a positive or negative } \\
\text { impact on drafting the sustainable reports within the BSE listed economic } \\
\text { entities on the Regulated Market. In this paper we resort to the rentability } \\
\text { rate (ARR) to measure the economic entities' profitability. ARR has been } \\
\text { used to determine the economic entities' performance regarding the }\end{array}$ \\
\hline
\end{tabular}




\begin{tabular}{|c|c|}
\hline & $\begin{array}{l}\text { investments made without knowing whether the entity accumulated debt } \\
\text { or used its own capital to invest. This measurement is the economic } \\
\text { entity's real performance. This report has calculated the relation between } \\
\text { the total profit before taxes and the total number of assets represented as } \\
\text { a percentage. The used calculation formula is the following: }\end{array}$ \\
ARR = (Net profit before taxes/ total assets) x 100 \\
\hline $\begin{array}{c}\text { The economic entity's } \\
\text { recognition (EER) }\end{array}$ & $\begin{array}{l}\text { This aspect refers to the recognition of the economic entity within the } \\
\text { community it operates in, or on a national or international level. Creating } \\
\text { a visible image of an economic entity leads to its involvement in actions } \\
\text { of social or environmental responsibility. } \\
\text { Through this variable one can determine whether the economic entities } \\
\text { have published, using their own website, recognized activity of ESG type. } \\
\text { Thus, a binominal form was used (1,0). If the economic entity reported } \\
\text { its awards and recognitions, it would receive, within the sustainable } \\
\text { report, a score of 1, otherwise it would receive a score of 0. }\end{array}$ \\
\hline
\end{tabular}

In the case of the control variable - the entity's objectives (EO), we are focused on the interest the economic entity manifests in relation to the social, economic and environment pylons which need to be expressed through the entity's mission and the non-financial information, component part of the performance's sustainable report. The economic entity's own objectives are appreciated using the score, as follows: a score of 1 is given to the entities which have a declaration of mission with the objectives referring to SR, otherwise, a score of 0 is given.

Starting from these considerations the following hypotheses have been issued:

H1: The economic entity's dimension has a significant impact within the content of the sustainable report of its performance.

H2: The economic entity's rentability has a significant impact on the sustainable report of its performance.

H3: The economic entity's recognition has a significant impact on the content of the sustainable report of its performance.

\subsection{Data analysis}

Within this paper, an analysis on the sustainable reports' content has been made so that they would include the requirements of the sustainable development reflected in the environment pylon, social pylon, and the economic pylon. Within the sample, one was interested in the content of the economic entities' sustainable report specific to 2019.

Data from a number of 83 BSE currently listed companies on the Regulated Market was gathered [24]. The analysis method of data presented within this study is through econometric models, processed using the SPSS and Microsoft Excel applications.

The content of the sustainable reports (SR) - dependant variable. These are measured using the score obtained by the presence of environmental, social and governance (ESG) information. In case the ESG elements are found within the sustainable report, a score of 1 is given, and if the contrary, the score is 0 . The SR has been determined using the following calculation formula:

Where:

$$
\mathrm{SR}=\left(\Sigma \mathrm{X}_{\mathrm{i}}\right) / \mathrm{n}_{\mathrm{i}}
$$

$\mathrm{n}_{\mathrm{i}}=$ number of elements

$\mathrm{X}_{\mathrm{i}}=1$ if ESG elements are present, 0 if ESG elements are not present, so that $0 \leq \mathrm{SR} \leq 1$. 


\subsection{Results}

The Descriptive Statistical Analysis represents a numerical quantitative description of a sample. Thus, in table 2, the information shows the minimum, maximum, average, and standard deviation for the dependant, independent and control variables in order to identify the relation between them:

Table 2. Descriptive statistical analysis

\begin{tabular}{|c|c|c|c|c|c|}
\hline Variable & $\begin{array}{c}\text { Economic } \\
\text { entities }\end{array}$ & Minimum & Maximum & Average & $\begin{array}{c}\text { Standard } \\
\text { deviation }\end{array}$ \\
\hline SR & 83 & 0.333333 & 1 & 0.895582329 & 0.179789932 \\
\hline ED & 83 & 6.547382 & 12.1198 & 8.543976792 & 0.975801558 \\
\hline ARR & 83 & -53722.7 & 844929.49 & 13733.78591 & 94029.72138 \\
\hline EER & 83 & 0 & 1 & 0.915662651 & 0.247971494 \\
\hline EO & 83 & 0 & 1 & 0.86746988 & 0.247971494 \\
\hline
\end{tabular}

According to table 2, SR is measured using an index based on the economic, social, environmental and governance (ESG) context. Based on the analysis in table 2, it shows that the total number of reported articles is of 0.9. The standard deviation is 0.179789932 which is smaller compared to the average. This result indicates the fact that more data is grouped around the average value.

For the second variable, the economic entity's dimension (ED), the average is of 8.543976792 (from 6.547382 to 12.1198). This average has been calculated using the $\lg$ (total assets of the economic entities) formula. Also, the standard deviation is 0.975801558 . The value of the standard deviation is smaller than the average, which means that more data is grouped around the average value.

The third variable, the rentability (ARR) with an average of 13733.78591 , is calculated using the economic entities' own capital rentability formula. Through this variable, one can prove that the economic entities which have obtained more profit are more sustainable. The rentability range has the smallest value of 53722.7 and the greatest value of 844929.49 . Its standard deviation is of 94029.72138 , which is greater than the average value. This indicates that less data is grouped around the average value.

The fourth variable regarding the recognition and the awards of the economic entity defined by EER has an average value of 0.915662651 , with a minimum value of 0 and a maximum of 1 . EER is measured using the disclosure index, which is 1 , represented by awards and recognitions, and 0 in case the entity does not have any awards nor recognitions. The standard deviation of EER (0.247971494) is smaller than its average (0.915662651) which means that more data is grouped around the average value.

Finally, table 2 also indicates descriptive statistics for the control variable, which in this study is given by the internal objectives of the economic entity (EO). This variable is measured with 1 for the presence of the internal objective and with 0 for the economic entity which has no internal objective. Based on the table above, the entity's objectives (EO) have an average of 0.86746988 (interval from 0 to 1 ) with the standard deviation value of 0.247971494 . This shows that more data is grouped around the average value.

\subsubsection{Correlation Coefficient}

Table 3 summarizes the correlation between the dependant and the independent variables. This confirms whether the company's dimension (ED), profitability (ARR) and the economic entity's objectives (EO) are tied to the sustainability report's index (SR). 
Table 3. Correlation coefficient between variables

\begin{tabular}{|c|c|}
\hline Variable & SR \\
\hline ED & 0.165246215 \\
\hline ARR & 0.07728437 \\
\hline EER & -0.015589478 \\
\hline EO & 0.50643137 \\
\hline
\end{tabular}

Based on the research of Rebekic et.al., [25], $r>0$ is known as positive relation, while $r$ $<0$ is known as negative relation, and $r=0$ is known as relation.

According to Table 3, ED is the most powerful correlation between the independent variables, while ARR is the weakest correlation. Based on the result, most of the independent variables have significant positive correlations. From Table 4, the economic entity's dimension (ED) has a positive relation with SR with an $r$ value of 0.165 (Sig. $=0,000)$. The economic entities which have an increased number of the total assets use SR within their business operations. Thus, the entity's dimension ED has an average positive linear relation with SR. Table 3 also shows that the ARR rentability has a positive relation with SR, having an $r$ value of 0.077 . The economic entities which have high profitability are preoccupied to use SR within their business operations. ARR is in a weak positive linear relation with SR.

Referring to table 3, the recognition or the accomplishments of the economic entity (EER) do not have a positive relation with SR, having a negative $r$ value of -0.015 . The entities which received awards and recognition are not more preoccupied to use SR within their business operations. EER has no linear relation with SR because the value of the correlation is closest to 0 .

Finally, the table above indicates the fact that the internal objectives of the economic entity (EO) have a positive relation with SR, with a positive $r$ value of 0.506 . The economic entities which have a declaration of mission or internal objectives for their business operations are more preoccupied with drafting sustainability reports (SR). The entity's objectives have a moderate positive relation with SR because the value of the correlation is closest to 0.506 . EO is the most powerful correlation between variables.

\subsubsection{Regression results}

According to Table 4 below, it shows that the influence of the economic entity's dimension (DE), the profitability (ARR) and the economic entity's accomplishments (EER) have an R square value of 0.27036 .

Table 4. Regression results

\begin{tabular}{|c|c|}
\hline Multiple R & 0.519969904 \\
\hline R Square & 0.270368701 \\
\hline Adjusted R Square & 0.232951711 \\
\hline Standard Error & 0.157462347 \\
\hline Observations & 83 \\
\hline
\end{tabular}

Using the regression, the independent variables can explain the fact that the general test has a $27.03 \%$ effect on the SR.

The ANOVA statistics for regressions test out the independent variables, detailed in Table 5. Judging by the table it results that the general regression model is significant due to the registered probabilities, these being smaller than the traditional $0,00 \%(0 \%)$, that is $5.289 \mathrm{E}$ $05<$ value of p. 
Table 5. ANOVA Test

\begin{tabular}{|l|r|c|c|c|r|}
\hline & $d f$ & $S S$ & $M S$ & $F$ & Significance $F$ \\
\hline Regression & 4 & 0.71663993 & 0.179159983 & 7.225827172 & $5.28939 \mathrm{E}-05$ \\
\hline Residual & 78 & 1.93396248 & 0.024794391 & & \\
\hline Total & 82 & 2.65060241 & & & \\
\hline
\end{tabular}

This aspect has as result a strong prognosis of the dependant variable's connection for every independent variable as well as the control variable. According to ANOVA, the F statistic is of 7.23, and the residual sum of the squares is 1.934 with a degree of freedom of 78.

\subsubsection{The multiple regression analysis}

The regression analysis in Table 6 shows the fact that out of the four independent variables, ARR has the biggest Beta value, of 8.776, indicating the fact that it has a bigger influence on SR.

EO has a Beta value of 0.358 , EER has 0.020 of Beta's value, and ED 0.019 of Beta, showing that it has the smallest Beta value compared to other independent variables.

Table 6. The regression analysis depending on SR

\begin{tabular}{|c|c|c|}
\hline Independent variables & Coefficients (Beta) & P-value (Significant Value) \\
\hline ED & 0.019 & 0.29 \\
\hline ARR & 8.776 & 0.66 \\
\hline EER & 0.020 & 0.77 \\
\hline EO & 0.358 & 2.84 \\
\hline
\end{tabular}

The results demonstrate that the rentability is the most influent variable in explaining the SR dependent variable. The analysis of regression depending on SR has registered significant values in the case of independent variables smaller than 0.05, that is ED and EO.

\subsubsection{Research results}

The research's results indicate the fact that the entity's three independent variables: the economic entities' dimension (ED), the economic entities' rentability (ARR) and the economic entities' accomplishments (EER) have a significant impact on drafting the sustainability report (SR). Most of the predictions made regarding the variables which influence SR are positive, excepting the economic entity's recognition which registered a negative value.

We can conclude that this study's variables, the dimension, the rentability and objectives the economic entity has, have the most powerful influence on the performance's sustainable report.

A clear highlighting of the objectives (EO) offers the economic entity a reliable approval from the relevant interested parties to consolidate the business relationship, inevitably improving the development degree in the long run. The economic entity's objectives have a social, environmental and governance (ESG) impact, being a perfect opportunity to present its social responsibility actions, because it establishes a clear proof of the economic entity's impact within an extremely competitive economic environment.

The recognition of the economic entities (EER) in relation with SR has a negative value, demonstrating this way that the entities' recognition does not affect the SR index's influence. 
From the economic entities' dimension (ED) in relation with SR it results that, once an entity develops, the level of sustainable reports grows to be able to contain every aspect of the environment, social and governance (ESG).

The rentability, ranked third in relation with SR, indicates the fact that the profitable economic entities use the sustainable reports to present the social, environmental and governance (ESG) effects. Therefore, the economic entities do not focus only on rentability to satisfy the needs of the interested parties, especially shareholders. In exchange, the third parties support the entities in presenting the sustainability reports based on ESG problems. A growing number of investors prefer to invest in transparent organizations because there is higher trust between managers and the interested parties, a more reliable prediction, and a lower risk of error in the informing process [26,27].

As a result, the whole case study highlights the SR as being a mean of communication between the economic entities and the interested parties on the diverse ESG specific domains.

\section{Discussions and conclusions}

This paper studied the influence of three independent variables as follows: the economic entity's dimension (ED), rentability (ARR) and the company's recognition (EER) in the process of drafting the sustainable reports' content (SR). In addition, the control variable is considered, consisting of the economic entity's objectives (EO) to find the relation with SR.

This study's results appreciate the impact of the companies' characteristics on the sustainable report of performance in the context of the sustainable development's exigencies. Moreover, this paper presents how the economic entity obtains a strategic advantage by providing non-financial information. When it comes to the process of report drafting, it includes a series of sustainable activities which encompasses the environment, social and governance and a series of other accomplishments of the economic entity, obtained according to the established objectives.

The importance of this study is given by the perspective given to the management to improve the annual reports and transform them into sustainable reports. Moreover, this study is benefited by the investors or the individuals interested in understanding how the economic entities respond to opportunities and manage risks.

Taking into account these considerations, the initially issued hypotheses can be validated or invalidated.

In the case of hypothesis H1: The economic entity's dimension has a significant impact on the content of its sustainable report of performance, it holds true, thus being validated. Validating this hypothesis results from the data obtained in Table 3 Correlation coefficient between variables, where ED is the most powerful correlation between the independent variables, having a positive linear relation of 0.165 .

In the case of hypothesis H2: The rentability of the economic entity has a significant impact within the content of the sustainable report of its performance, it holds true, thus being validated. Validating this hypothesis results from the data obtained in Table 3 Correlation coefficient between variables, where ARR, even though the weakest correlation, with an SR of 0.077 , is in a weak positive linear relation with SR.

In the case of hypothesis $H 3$ : The recognition of the economic entity has a significant impact on the content of the sustainable report of its performance, it does not hold true, thus being invalidated. The invalidation of this hypothesis results from the data obtained in Table 3 Correlation Coefficient between variables, where EER has a negative value of -0.015 in relation to SR.

The research's originality and innovation are a result of the manner in which the impact of the companies' characteristics is approached regarding the sustainable report of performance in the context of sustainable development, having as case study the Bucharest 
Stock Exchange listed companies. With the help of the research methods that were used, referring to the paper's content and the contribution that was brought, the research can be considered a documentary type paper.

A series of limitations have been identified within the paper. One of the limitations refers to the concept of sustainable reports which is in an early stage in Romania, even though the sample has been composed of BSE listed economic entities. Another limitation can be represented by the subjectivity of the authors regarding the content of the sustainable reports and the fact that the reference period of data collection is of one year. In order to overcome these limitations, research regarding new dimensions of the sample can be made or utilising an even longer observation period to reduce the limitation of data collection and to help researchers to a better understanding regarding provided data interpretation within the sustainable reports, a better knowledge of the characteristics, the management system and the objectives specific to the entity.

In conclusion, we appreciate the content of the sustainable report as being important for the Romanian economic entities to be able to support their activity, the long-term competitiveness and to attract investors.

\section{References}

1. V. Danciu, Theoretical and Applied Economics, 9, 586 (2013)

2. S. Gokten, Y. Ozerhan, P.O. Gokten, Theoretical Journal of Accounting 107 (163), 99-118 (2020)

3. R.G. Eccles, M.P. Krzus, J.G. Rogers, G. Serafeim, Journal of Applied Corporate Finance, 24 (2), 65-71 (2012)

4. M. Zahid, Z. Ghazali, Z. H. Rehman, International Journal of Economics and Financial Issues, 6 (2), (2016)

5. M. Man, M.M. Bogeanu-Popa, Sustainability, 12 (6), 2179 (2020) doi:10.3390/su12062179; eISSN: 2071-1050

6. Directive 2014/34/EU (2014)

7. C.D. Hategan, R.I. Curea-Pitorac, V.P. Hategan. Int. J. Environ. Res. Public Health 17, 8526 (2020) https://doi.org/10.3390/ijerph17228526

8. I. Pop (Anghel), M. Man Proceedings of the 29th. International Business Information Management Conference IBIMA2017 29, 3700-3705 (2017) ISBN:978-0-9860419-7-6

9. E.I. Ion, M. Man Proceedings of the 31st International Business Information Management Conference IBIMA2018 31, 2115-2124 (2018) ISBN: 978-0-9998551-0-2

10. E. Nechita, Audit Financiar, 3 (155), (2019)

11. M.M. Bogeanu-Popa, M. Man Bulletin of Taras Shevchenko National University of Kyiv. Economics, 3 (210) 12-19 (2020)

12. N.M. Aris, S.M. Yusof, N.I.I. Idris, N.S. Zaidi, R. Anuar International Journal of Academic Research in Business and Social Sciences 11(14), 1-20 (2021)

13. A. Măcriş, M. Măcriş, Annals of University of Petrosani-Economics, Economics X (IV), 181-192 (2010) ISSN 1582-5949

14. M. Măcriș, International Journal of Management Sciences and Business Research 2 (3), 33-48 (2013) ISSN: 2226-8233

15. V. Roblek, O. Thorpe, M. Pejic Bach, A. Jerman, M. Meško, Sustainability 12 (20), 8497 (2020) DOI: $10.3390 /$ su 12208497

16. C.A. Ştefănescu, A. Tiron-Tudor, E.M. Moise, Journal Of Business Economics And Management 22 (1), 257-276 (2021) https://doi.org/10.3846/jbem.2020.13479

17. S. Aureli, E. Magnaghi, F. Salvatori, Accounting in Europe 16 (3), 290-312 (2019) https://doi.org/10.1080/17449480.2019.1637529

18. H.T. Nguyen, T.T.M. Ho, D.M.D. Le, P.M. Nguyen, D.T. Tran, Cogent Business \& Management 7 (1), 1816417 (2020) https://doi.org/10.1080/23311975.2020.1816417

19. S. Gokten, Y. Ozerhan, P.O. Gokten, Theoretical Journal of Accounting 107 (163), 99-118 (2020) https://doi.org/10.5604/01.3001.0014.2466 
20. D. Coluccia, S. Fontana, S. Solimene, Sustainability, 10 (8), 2823 (2018) https://doi.org/10.3390/su10082823

21. V.T.T Thao, N.H. Tien, D.B.H. Anh, Journal of Advanced Research in Management, 1 (19), $17-$ 29 (2019) DOI:10.14505/jarmv10.1(19).02.

22. C. Carini, L. Rocca, M. Veneziani, C. Teodori, Sustainability, 10 (2), 560 (2018) https://doi.org/10.3390/su10020560

23. P. Buys, M. Oberholzer, P. Andrikopoulos,. Journal of Social Sciences, 29 (2), 151-158 (2011)

24. Bursa de Valori București (BVB). Available on https://www.bvb.ro/Financial Instruments/SelectedData/CurrentReports\#

25. A. Rebekic, Z. Loncaric, S. Petrovic, S. Maric, Poljoprivreda/Agriculture 21 (2), 47-54 (2015) https://doi.org/10.18047/poljo.21.2.8

26. J. Dumay, M. La Torre, F. Farneti, Journal of Intellectual Capital, 20 (1), 11-39 (2019) https://doi.org/10.1108/JIC-06-2018-0097

27. A. Venturelli, F. Caputo, S. Cosma, R. Leopizzi, S. Pizzi, Sustainability, 9 (8), 1385 (2017) https://doi.org/10.3390/su9081385 